Cite this: Soft Matter, 2014, 10, 3970

\title{
Solution properties and electrospinning of phosphonium gemini surfactants $\dagger$
}

\author{
Sean T. Hemp, Amanda G. Hudson, Michael H. Allen, Jr., Sandeep S. Pole, \\ Robert B. Moore and Timothy E. Long*
}

Bis(diphenylphosphino)alkanes quantitatively react with excess 1-bromododecane to prepare novel phosphonium gemini surfactants with spacer lengths ranging from 2 to 4 methylenes (12-2/3/4-12P). Dodecyltriphenylphosphonium bromide (DTPP), a monomeric surfactant analog, was readily water soluble, however, in sharp contrast, phosphonium gemini surfactants were poorly soluble in water due to two hydrophobic tails and relatively hydrophobic cationic head groups containing phenyl substituents. Isothermal titration calorimetry did not reveal a measurable critical micelle concentration for the 12-2$12 \mathrm{P}$ phosphonium gemini surfactant in water at $25^{\circ} \mathrm{C}$. Subsequent studies in 50/50 v/v water-methanol at $25{ }^{\circ} \mathrm{C}$ showed a $\mathrm{CMC}$ of $1.0 \mathrm{mM}$ for $12-2-12 \mathrm{P}$. All phosphonium gemini surfactants effectively complexed nucleic acids, but failed to deliver nucleic acids in vitro to HeLa cells. The solution behavior of phosphonium gemini surfactants was investigated in chloroform, which is an organic solvent where reverse micellar structures are favored. Solution rheology in chloroform explored the solution behavior of the phosphonium gemini surfactants compared to DTPP. The 12-2-12P and 12-3-12P gemini surfactants were successfully electrospun from chloroform to generate uniform fibers while $12-4-12 \mathrm{P}$ gemini surfactant and DTPP only electrosprayed to form droplets.

Received 4th February 2014

Accepted 27th March 2014

DOI: $10.1039 / \mathrm{c} 4 \mathrm{sm} 00271 \mathrm{~g}$

www.rsc.org/softmatter synthesized bis(alkyl-1,3-diene)-containing phosphonium gemini surfactants with methyl substituents in the head groups. Alkyl tail lengths and spacer lengths directly impacted the selfassembly of the phosphonium gemini surfactants into lyotropic liquid crystalline phases. The terminal diene groups on each tail enabled the crosslinking of the liquid crystalline materials, and the crosslinked gemini surfactants maintained their liquid crystalline phase. Gin and coworkers ${ }^{18}$ engineered a crosslinked composite containing the phosphonium gemini surfactant to generate a highly efficient water purification membrane.

Candau et $a .^{19}$ reported three theoretical concentration regimes for surfactants in solution: (1) a dilute regime with slow micellar growth, (2) a semidilute regime wherein the micelles rapidly grow in size, and (3) a concentrated regime where the net charge on the micelle end-caps directly impacts aggregation number. $\mathrm{C}^{*}$ and $\mathrm{C}^{* *}$ correspond to transitions in the concentration regimes from the dilute to semidilute regime or semidilute to concentrated regime, respectively. Long et $a .^{20}$ examined the solution behavior of a common ammonium gemini surfactant termed 12-2-12A where 2 represents an ethylene spacer with methyl substituents on the cationic head groups. In water, the 12-2-12A surfactant displayed all three concentration regimes and cryo-TEM showed a change in micellar structure between each regime. The scaling factors increased from the dilute regime to the concentrated regime due to enhanced micellar overlap at higher concentrations, leading to higher viscosities. This manuscript strives to directly
Macromolecules and Interfaces Institute, Department of Chemistry, Virginia Tech, Blacksburg, VA 24061, USA. E-mail: telong@vt.edu; Fax: +1 (540)231-8517; Tel: +1 (540)231-2480

$\dagger$ Electronic supplementary information (ESI) available. See DOI: $10.1039 / \mathrm{c} 4 \mathrm{sm} 00271 \mathrm{~g}$ 
examine phosphonium gemini surfactants for their solution and electrospinning behavior.

Electrospinning of polymers from solution or melt is a versatile method to generate sub-micron, non-woven fibrous mats suitable for a broad range of applications including filtration and tissue scaffolds. ${ }^{21}$ During the electrospinning process, the polymer solution is electrified and extruded from a needle whereupon it accelerates towards a grounded or electrified target. ${ }^{22}$ Charge repulsion within the jet results in stretching and thinning of the fluid until reaching the target and subsequent solidification. ${ }^{23}$ The polymer must sufficiently stabilize the electrospinning jet to achieve uniform fibers. ${ }^{24}$ Chain entanglements play a primary role in stabilizing the electrospinning jet, and if the polymer concentration is insufficient to achieve sufficient chain entanglements, electrospraying will occur. ${ }^{25}$ Long et al. ${ }^{26}$ first reported the successful electrospinning of a low molar mass surfactant. The phospholipid mixture, soy lecithin, self-assembled into worm-like micelles in organic solution and sufficiently entangled at higher concentrations similar to polymer chains, stabilizing the electrospinning jet and generating uniform fibers. Long et al. ${ }^{20}$ later extended electrospinning of low molar mass molecules to a common ammonium gemini surfactant (12-2-12A) demonstrating the impact of the supramolecular assembly on electrospinning behavior. Other researchers also have subsequently reported the electrospinning of other small molecules, ${ }^{27-31}$ however, the electrospinning of phosphonium gemini surfactants remains unprecedented.

We report herein the synthesis and characterization of novel phosphonium gemini surfactants with phenyl-containing head groups, wherein the alkyl spacer between the head groups varied between 2-4 methylenes. Thermogravimetric analysis and differential scanning calorimetry explored the thermal properties of the phosphonium gemini surfactants. The solution behavior of the phosphonium gemini surfactants was examined in both aqueous and organic solutions. Dynamic light scattering and isothermal titration calorimetry examined their aqueous solution behavior. Solution rheology probed the solution behavior of the phosphonium gemini surfactants in organic solvents across a broad concentration regime, and this report describes the successful electrospinning of the phosphonium gemini surfactants to form fibers.

\section{Experimental section}

\section{Materials}

1,2-Bis(diphenylphosphino)ethane (99\%), 1,3-bis(diphenylphosphino)propane (97\%), 1,4-bis(diphenylphosphino)butane (98\%), dodecyltriphenylphosphonium bromide (98\%), and 1bromododecane (97\%) were obtained from Sigma-Aldrich and used as received. All solvents were obtained from Sigma-Aldrich and used as received.

\section{Analytical methods}

${ }^{1} \mathrm{H}$ and ${ }^{31} \mathrm{P}$ nuclear magnetic resonance (NMR) spectroscopy was performed in $\mathrm{CDCl}_{3}$ using a Varian Unity 400 spectrometer operating at $400 \mathrm{MHz}$. Mass spectrometry was accomplished using an Agilent 6220 LC-TOF Mass Spectrometer. Thermogravimetric analysis (TGA) was completed using a TA Instruments TGA Q50 operating at a $10^{\circ} \mathrm{C} \mathrm{min}^{-1}$ ramp from $25^{\circ} \mathrm{C}$ to $600{ }^{\circ} \mathrm{C}$. Differential scanning calorimetry (DSC) was accomplished using a TA Instruments DSC Q1000 with a heat/cool/heat cycle. Solution rheology was completed using a TA Instruments DHR2 strain-controlled rheometer with a concentric cylinder and solution cup geometry. Zero-shear viscosities were obtained from the Newtonian plateau in shear sweep experiments. Scanning electron microscopy (SEM) was performed using a Nikon Jeol SEM operating at $10 \mathrm{kV}$ under high vacuum. Dynamic light scattering (DLS) was conducted using a Malvern Zetasizer Nano operating at $25^{\circ} \mathrm{C}$.

Isothermal titration calorimetry (ITC) measurements were performed with a TA Instruments low volume Nano ITC. The Nano ITC employs a gold reference cell and a sample cell with a fixed volume of $190 \mu \mathrm{L}$ and a $50 \mu \mathrm{L}$ gas tight syringe. Duplicate titrations were performed with a sample cell containing ultrapure water, and the injection syringe contained a $0.11 \mathrm{mM}$ solution of sample 12-2-12P. The ITC was maintained at $25{ }^{\circ} \mathrm{C}$ with a $350 \mathrm{rpm}$ stir rate and aliquots of $1.43 \mu \mathrm{L}$ were injected into the sample cell at an interval of $300 \mathrm{~s}$ between injections. For measurements with a mixed solvent system, the sample cell was filled with a mixture of $50 / 50 \mathrm{v} / \mathrm{v}$ water-methanol. The injection syringe was filled with an $8.05 \mathrm{mM}$ solution of sample 12-2-12P in the identical $50 / 50 \mathrm{v} / \mathrm{v}$ water-methanol mixture. Injections of the surfactant solution were titrated into the cell in $1.99 \mu \mathrm{L}$ aliquots with $300 \mathrm{~s}$ intervals between each injection. The CMC value was determined as the surfactant concentration at the inflection point of the heat versus concentration profile. The first derivative of $Q$ versus [surfactant] was used to facilitate a precise determination of the inflection point.

\section{Synthesis of 12-2-12P phosphonium gemini surfactant}

1,2-Bis(diphenylphosphino)ethane (24.85 g, $62.4 \mathrm{mmol}), 1$-bromododecane $(62.65 \mathrm{~g}, 251.4 \mathrm{mmol})$, and ethanol $(300 \mathrm{~mL})$ were added to a $500 \mathrm{~mL}$, round-bottomed flask with a magnetic stir bar. The solution was purged with argon for $1 \mathrm{~h}$ and subsequently heated at $80{ }^{\circ} \mathrm{C}$ for 3 days. The solution was concentrated in vacuo to obtain a viscous liquid. The viscous liquid was added dropwise to $3 \mathrm{~L}$ of hexanes to precipitate the gemini surfactant. The gemini surfactant was filtered and washed with $300 \mathrm{~mL}$ hexanes three times. The 12-2-12P surfactant was dried in vacuo at $70{ }^{\circ} \mathrm{C}$ for 2 days $\left(46.00 \mathrm{~g}, 82.2 \%\right.$ yield). ${ }^{1} \mathrm{H}$ NMR $\left(400 \mathrm{MHz}, \mathrm{CDCl}_{3}\right) \delta 8.10(\mathrm{q}, 8 \mathrm{H}, \mathrm{ArH}), 7.72(\mathrm{t}, 4 \mathrm{H}, \mathrm{ArH}), 7.64$ $(\mathrm{t}, 8 \mathrm{H}, \mathrm{ArH}), 3.67\left(\mathrm{~m}, 4 \mathrm{H},-\mathrm{PCH}_{2} \mathrm{CH}_{2} \mathrm{P}-\right), 3.58\left(\mathrm{~m}, 4 \mathrm{H},-\mathrm{PCH}_{2}-\right)$, $1.43\left(\mathrm{~m}, 4 \mathrm{H},-\mathrm{CH}_{2}-\right), 1.14\left(\mathrm{~m}, 36 \mathrm{H},-\mathrm{CH}_{2}-\right), 0.83\left(\mathrm{t}, 6 \mathrm{H},-\mathrm{CH}_{3}\right)$. ${ }^{31} \mathrm{P}$ NMR $\left(\mathrm{CDCl}_{3}\right) \delta 30.68$. Mass spectrometry: theoretical, $\mathrm{m} / \mathrm{z}$ 368.2627; experimental, $\mathrm{m} / \mathrm{z} 368.2659$.

\section{Synthesis of 12-3-12P phosphonium gemini surfactant}

1,3-Bis(diphenylphosphino)propane (21.16 g, $51.3 \mathrm{mmol}$ ), 1-bromododecane (53.95 g, $216.5 \mathrm{mmol})$, and ethanol (300 mL) were added to a $500 \mathrm{~mL}$, round-bottomed flask equipped with a magnetic stir bar. After purging the solution with $\operatorname{argon}$ for $1 \mathrm{~h}$, 
the solution was heated at $80{ }^{\circ} \mathrm{C}$ for 3 days. After concentrating the solution in vacuo, the viscous liquid was added to $3 \mathrm{~L}$ hexanes to obtain the solid 12-3-12P surfactant. The solid was filtered using a water aspirator and rinsed with $300 \mathrm{~mL}$ hexanes three times. The 12-3-12P surfactant was dried in vacuo at $70{ }^{\circ} \mathrm{C}$ for 2 days (42.98 g, 92.0\% yield). ${ }^{1} \mathrm{H}$ NMR (400 $\left.\mathrm{MHz}, \mathrm{CDCl}_{3}\right) \delta$ 7.93 (m, 8H, ArH), 7.67 (m, 4H, ArH), 7.61 (m, 8H, ArH), 3.75 $\left(\mathrm{m}, 4 \mathrm{H},-\mathrm{PCH}_{2}\right), 3.27\left(\mathrm{~m}, 4 \mathrm{H},-\mathrm{PCH}_{2}-\right), 2.03\left(\mathrm{~m}, 2 \mathrm{H},-\mathrm{CH}_{2}-\right) 1.44$ $\left(\mathrm{m}, 8 \mathrm{H},-\mathrm{CH}_{2}-\right), 1.15\left(\mathrm{~m}, 32 \mathrm{H},-\mathrm{CH}_{2}-\right), 0.84\left(\mathrm{t}, 6 \mathrm{H},-\mathrm{CH}_{3}\right) .{ }^{31} \mathrm{P}$ NMR $\left(\mathrm{CDCl}_{3}\right) \delta$ 27.16. Mass spectrometry: theoretical, $\mathrm{m} / \mathrm{z}$ 375.2706; experimental, $m / z$ 375.2704.

\section{Synthesis of 12-4-12P phosphonium gemini surfactant}

1,4-Bis(diphenylphosphino)butane (25.04 g, $58.7 \mathrm{mmol})$, 1-bromododecane (59.64 g, $239.3 \mathrm{mmol})$, and ethanol (300 mL) were added to a $500 \mathrm{~mL}$, round-bottomed flask containing a magnetic stir bar. The solution was heated to $80{ }^{\circ} \mathrm{C}$ for 3 days after purging with argon for $1 \mathrm{~h}$. A majority of the ethanol was removed in vacuo and the viscous liquid was added dropwise to 3 L hexanes. A resulting yellow oil was obtained, which was washed with $3 \mathrm{~L}$ hexanes three times to induce solidification. The resulting solid was filtered to obtain the 12-4-12P surfactant. The surfactant was dried in vacuo at $70{ }^{\circ} \mathrm{C}$ for 2 days (44.80 g, 82.5\% yield). ${ }^{1} \mathrm{H}$ NMR $\left(400 \mathrm{MHz}, \mathrm{CDCl}_{3}\right) \delta 7.91(\mathrm{~m}, 8 \mathrm{H}$, $\mathrm{ArH}), 7.70$ (m, 4H, ArH), 7.65 (m, 8H, ArH), 3.57 (m, 4H, $-\mathrm{PCH}_{2}$ ), $3.12\left(\mathrm{~m}, 4 \mathrm{H},-\mathrm{PCH}_{2}-\right), 1.93\left(\mathrm{~m}, 4 \mathrm{H},-\mathrm{CH}_{2}-\right) 1.45\left(\mathrm{~m}, 8 \mathrm{H},-\mathrm{CH}_{2}-\right)$, $1.16\left(\mathrm{~m}, 32 \mathrm{H},-\mathrm{CH}_{2}-\right), 0.84\left(\mathrm{t}, 6 \mathrm{H},-\mathrm{CH}_{3}\right) .{ }^{31} \mathrm{P} \mathrm{NMR}\left(\mathrm{CDCl}_{3}\right) \delta$ 28.24. Mass spectrometry: theoretical, $m / z$ 382.2784; experimental, $m / z$ 382.2777.

\section{Electrospinning}

All phosphonium surfactants were electrospun from solutions of chloroform using a syringe pump to control the flow rate at $1 \mathrm{~mL} \mathrm{~h}^{-1}$. The surfactant solution was electrified at $+20 \mathrm{kV}$ with one power supply while the aluminum foil target was electrified at $-15 \mathrm{kV}$ using another power supply to generate an overall potential difference of $35 \mathrm{kV}$. The target was $15 \mathrm{~cm}$ from the syringe needle. After electrospinning, the fibers were imaged using SEM and 20 fibers were measured to obtain the average fiber diameter and standard deviation.

\section{Polyplex formation and characterization}

Phosphonium gemini surfactants displayed poor water solubility, requiring the dissolution of the surfactants in water at $0.1 \mathrm{mg} \mathrm{mL}^{-1}$ concentrations. The heterogenous solutions were sealed and heated to $100{ }^{\circ} \mathrm{C}$ for $1 \mathrm{~h}$ to generate homogenous solutions and then subsequently cooled to room temperature. DNA gel shift assays were performed as follows. Plasmid DNA (gWiz-Luc, Aldevron, $0.2 \mu \mathrm{g}$ ) was complexed with the required amount of phosphonium gemini surfactant to obtain the desired charge ratio in $28 \mu \mathrm{L}$ total volume of water for $30 \mathrm{~min}$. Loading buffer (30 wt\% glycerol in water, $2 \mu \mathrm{L}$ ) was added and then $20 \mu \mathrm{L}$ of the polyplex solutions was loaded in a $1 \mathrm{wt} \%$ agarose gel stained with $6 \mu \mathrm{L}$ SYBR Green I (Sigma-Aldrich). The gel was metered at $70 \mathrm{~V}$ for $30 \mathrm{~min}$ and subsequently imaged using a MultiDoc-it Digital Imaging System (UVP).

\section{Cell culture}

Human cervical cancer cells (HeLa) were cultured at $37{ }^{\circ} \mathrm{C}$ and $5 \% \mathrm{CO}_{2}$ in a saturated humid environment. The cells were grown in Dulbecco's modified Eagle's media (DMEM) supplemented with $10 \%$ fetal bovine serum (FBS), $100 \mathrm{U} \mathrm{mL}^{-1}$ penicillin, and $100 \mu \mathrm{g} \mathrm{mL} \mathrm{m}^{-1}$ streptomycin. All reagents were obtained from MediaTech and used as received.

\section{Luciferase assay}

Polyplex solutions were prepared as follows for transfection. Plasmid DNA (5 $\mu \mathrm{g})$ was diluted into $\mathrm{H}_{2} \mathrm{O}(250 \mu \mathrm{L}$ total volume). Phosphonium gemini surfactants $(250 \mu \mathrm{L})$ at the appropriate concentration to generate the desired charge ratio when added to the DNA solution were also prepared. The surfactant solution was added to the pDNA solution and incubated for $30 \mathrm{~min}$.

HeLa cells ( $500 \mu \mathrm{L}, 100000$ cells per $\mathrm{mL}$ ) were plated in 24-well plates $24 \mathrm{~h}$ prior to transfection. The complete media was aspirated and the cells were rinsed with $300 \mu \mathrm{L}$ HBSS. After the addition of $400 \mu \mathrm{L}$ DMEM to each well, $100 \mu \mathrm{L}$ of the polyplex solution was added to the well $(1 \mu \mathrm{g}$ DNA per well). Lipofectamine 2000 and Jet-PEI formulations followed recommended manufacturer's protocols. The cells were transfected for $4 \mathrm{~h}$ and then the transfection media was aspirated. Complete media $(500 \mu \mathrm{L})$ was added to each well and the cells were incubated for $44 \mathrm{~h}$. Each well was rinsed with $300 \mu \mathrm{L}$ PBS and the cells were subsequently lysed with $120 \mu \mathrm{L} 1 \times$ Promega lysis buffer. The plates were incubated for $30 \mathrm{~min}$ and then subjected to two freeze-thaw cycles. A Promega luciferase kit was utilized following manufacturer's instructions to quantify luciferase expression. Luciferase transfection was reported as relative light units (RLU) and the transfections were performed in quadruplicate. Student's $t$-test was performed to determine statistical significance at a 95\% confidence interval.

\section{Results and discussion}

\section{Synthesis}

Our group previously reported the synthesis of high molecular weight phosphonium ionenes from the well-defined stepgrowth polymerization of bis(diphenylphosphino)alkanes and alkyl dibromide monomers. ${ }^{32}$ A logical extension of this research focused on the synthesis of novel phosphonium gemini surfactants wherein a monofunctional alkyl bromide, 1-bromododecane, was utilized to alkylate the bis(diphenylphosphino)alkanes to generate the desired gemini surfactants. Scheme 1 depicts the synthetic strategy to generate phosphonium gemini surfactants. Gemini surfactants are commonly named $x-y-x$ wherein $x$ corresponds to the alkyl length of the tail and $y$ correlates to the spacer length in between the cationic head groups. 12-y-12P phosphonium gemini surfactants were prepared with $y=2-4$ to examine the influence of the alkyl spacer length on solution behavior. All gemini surfactants were synthesized using a 4 molar excess of 1 -bromododecane at $80{ }^{\circ} \mathrm{C}$ in ethanol for 3 days to ensure complete alkylation and minimal monoalkylation. Dodecyltriphenylphosphonium bromide 


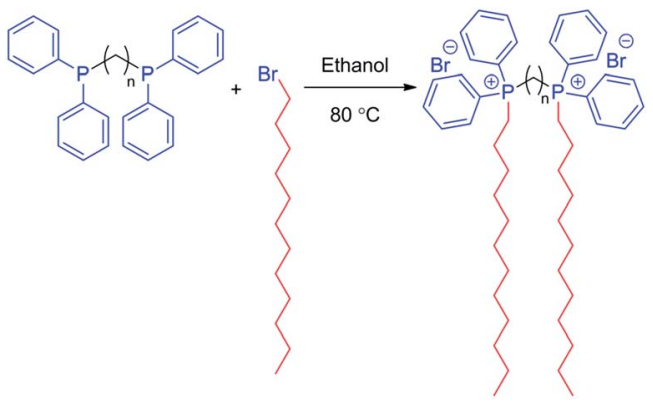

Scheme 1 Synthesis of phosphonium gemini surfactants.

(DTPP) served as a monofunctional surfactant control for comparison to the phosphonium gemini surfactants.

TGA and DSC examined the thermal stability and thermal transitions of the phosphonium gemini surfactants compared to the DTPP control surfactant (Table 1). 12-2-12P gemini surfactant displayed the lowest thermal stability due to the proximity of the phosphonium head groups, which decreased the surfactant thermal stability. Interestingly, 12-3-12P and 124-12P gemini surfactants exhibited improved thermal stability compared to DTPP. DSC analysis elucidated both the melting point and glass transition temperature of all surfactants. The melting point was obtained from the first heat, and the glass transition temperature was determined from the second heat. The gemini surfactant $T_{\mathrm{g}}$ decreased as the spacer length increased, and the $T_{\mathrm{m}}$ increased as the spacer length increased.

\section{Gemini surfactants in water}

DTPP is readily water soluble and displays a CMC of $1.80 \mathrm{mM}$ in water. ${ }^{33}$ Phosphonium gemini surfactants displayed poor water solubility, presumably due to the hydrophobic nature of the phenyl-containing head groups and the hydrophobic tails attached to the two head groups. Phosphonium gemini surfactants dissolved in water at $0.1 \mathrm{mg} \mathrm{mL}^{-1}$ concentrations after heating at $100{ }^{\circ} \mathrm{C}$ for $1 \mathrm{~h}$. Dynamic light scattering (DLS) experiments probed the solution structure of the phosphonium gemini surfactants in water at $0.1 \mathrm{mg} \mathrm{mL}^{-1}$ concentrations. Fig. 1 highlights the DLS traces for 12-2-12P and 12-3-12P phosphonium gemini surfactants. The size of the aggregates for 12-2-12P and 12-3-12P were $117 \pm 2 \mathrm{~nm}$ and $105 \pm 8 \mathrm{~nm}$, respectively, with monomodal, narrow distributions. 12-4-12P gemini surfactant failed to display well-defined aggregates in aqueous solution based on DLS analysis.

Table 1 Thermal properties of phosphonium gemini surfactants

\begin{tabular}{llcl}
\hline Gemini surfactant & $T_{\mathrm{g}}{ }^{a}\left({ }^{\circ} \mathrm{C}\right)$ & $T_{\mathrm{m}}{ }^{a}\left({ }^{\circ} \mathrm{C}\right)$ & $T_{\mathrm{d}, 5 \%}{ }^{b}\left({ }^{\circ} \mathrm{C}\right)$ \\
\hline DTPP & 25 & 102 & 274 \\
$12-2-12 P$ & 57 & 64 & 264 \\
$12-3-12 P$ & 52 & 109 & 300 \\
$12-4-12 P$ & 47 & 135 & 305
\end{tabular}

${ }^{a}$ TA DSC Q1000, heat/cool/heat, $10{ }^{\circ} \mathrm{C} \mathrm{min}^{-1} \cdot{ }^{b} \mathrm{TA}$ TGA Q50, $10{ }^{\circ} \mathrm{C}$ $\min ^{-1}$.

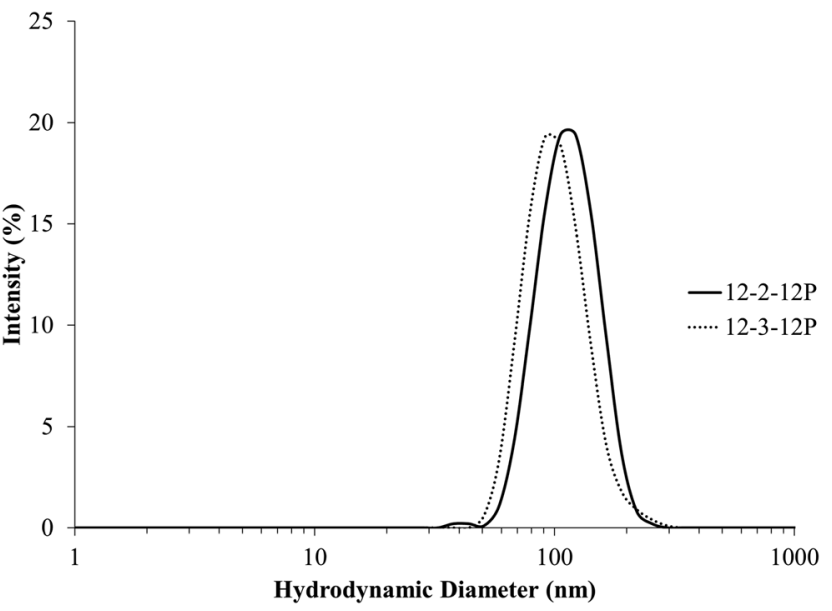

Fig. 1 Dynamic light scattering of $12-2-12 \mathrm{P}$ and $12-3-12 \mathrm{P}$ phosphonium gemini surfactants in $0.1 \mathrm{mg} \mathrm{mL}^{-1}$ aqueous solutions.

Critical micelle concentrations (CMCs) are a fundamental property of all surfactants and multiple techniques including fluorescence spectroscopy, ${ }^{34}$ conductivity, ${ }^{35}$ and ITC $^{36}$ enable the determination of CMCs accurately. Initial experiments to determine the CMC of phosphonium gemini surfactants focused on fluorescence spectroscopy and conductivity methods to determine CMCs. Unfortunately, both methods failed to determine the CMC of phosphonium gemini surfactants. The Krafft temperature, also called the critical micellization temperature, corresponds to the temperature necessary for the surfactant to micellize in solution. ${ }^{37}$ Below the Krafft temperature, the surfactant fails to display a CMC. The phosphonium gemini surfactants presumably exhibited a very high Krafft temperature due to the hydrophobic tails and hydrophobic phenyl-containing head groups. Furthermore, the process for solution preparation required $100{ }^{\circ} \mathrm{C}$ for $1 \mathrm{~h}$ to generate $0.1 \mathrm{mg} \mathrm{mL}^{-1}$ gemini surfactant solutions, suggesting a high Krafft temperature. The aqueous phosphonium gemini surfactant solutions were also metastable, and the solutions would become cloudy after extended aging, highlighting a Krafft temperature above room temperature. All experiments were performed shortly after preparing the aqueous solutions to minimize surfactant concentration changes and the effects of aging. Future work will examine the solubility of phosphonium gemini surfactants in aqueous solution to further understand the interplay of the Krafft temperature on micellization behavior.

Isothermal titration calorimetry (ITC) is one of the most effective methods to determine the CMC of a surfactant along with other thermodynamic information regarding the micellization behavior. ${ }^{36}$ Fig. 2 depicts ITC experiments performed for 12-2-12P in water and a 50/50 v/v water-methanol solution. The titration of a concentrated 12-2-12P aqueous solution into water resulted in titration curves similar to the titration of water into water suggesting the absence of appreciable demicellization in pure water at $25{ }^{\circ} \mathrm{C}$. This behavior is again consistent with the presumed high Krafft temperature for these gemini surfactants. In contrast, titrations performed in 50/50 v/v water-methanol 

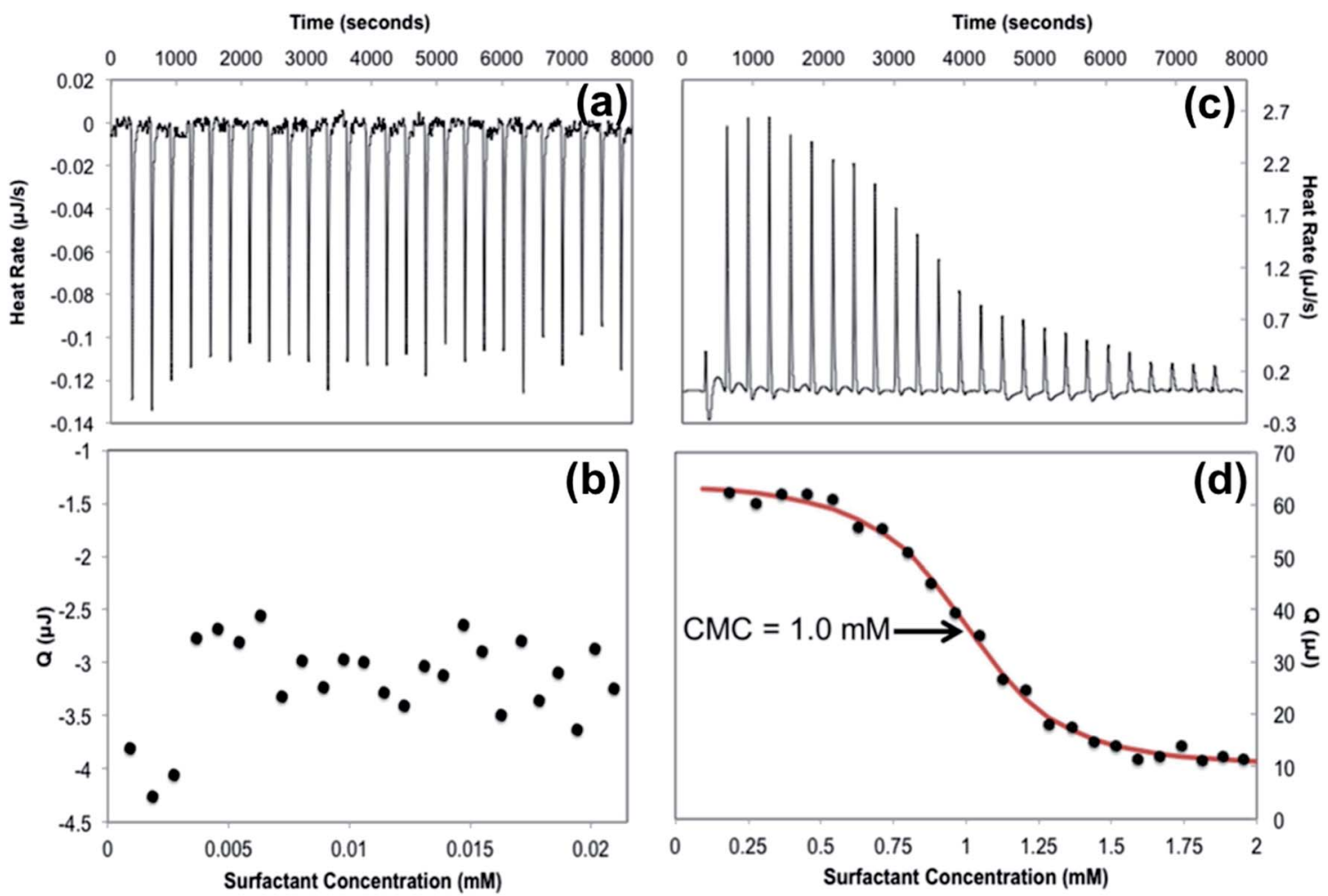

Fig. 2 Isothermal titration calorimetry of 12-2-12P gemini surfactant: (a) enthalpogram in pure water, (b) integrated heat per injection in pure water, (c) enthalpogram in 50/50 v/v water-methanol, and (d) integrated heat per injection in 50/50 v/v water-methanol.

resulted in titration curves that are representative of conventional surfactant CMC behavior, as shown in Fig. 2d. Based on this unique ITC approach, the CMC for $12-2-12 \mathrm{P}$ in $50 / 50 \mathrm{v} / \mathrm{v}$ water-methanol was found to be $1.0 \mathrm{mM}$ at $25^{\circ} \mathrm{C}$. The addition of methanol resulted in improved solubility of the phosphonium gemini surfactants and enabled the determination of the CMC using ITC. Further work will develop a method to extrapolate the CMC of phosphonium gemini surfactants to that in pure water through a series of ITC experiments using variable concentrations of water-methanol.

DNA gel shift assays and luciferase transfection assays examined the suitability of phosphonium gemini surfactants as nonviral nucleic acid delivery agents. The complexation of a cationic surfactant and negatively-charged nucleic acid in solution generates nanoparticles or aggregates called lipoplexes. Fig. 3 shows DNA gel shift assays for all phosphonium gemini surfactants, which confirmed the efficacy of

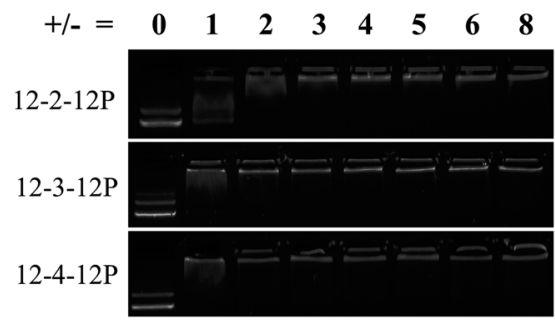

Fig. 3 DNA gel shift assays for phosphonium gemini surfactants. phosphonium gemini surfactants to bind nucleic acids. The charge ratio ( \pm ratio) was defined as the moles of cationic head groups in the surfactant to the moles of negatively-charged phosphate groups in the plasmid DNA backbone. All phosphonium gemini surfactants bound nucleic acids with 12-2-12P, 12-3-12P, and 12-4-12P binding plasmid DNA completely at \pm ratios of 3,2, and 2, respectively. Luciferase transfection experiments in serum-free media elucidated low transfection efficiency of phosphonium gemini surfactants compared to common positive controls, Jet-PEI and Lipofectamine 2000 (Fig. 4).

\section{Gemini surfactants in chloroform}

The goal of generating electrospun fibers composed of the phosphonium gemini surfactants required an examination of the solution behavior of phosphonium gemini surfactants in organic solutions to provide information necessary for electrospinning. Phosphonium gemini surfactants displayed excellent solubility in organic solvents except for hexanes. Chloroform was chosen as the solvent to examine the solution properties of phosphonium gemini surfactants due to its ability to dissolve the surfactants and its necessary volatility for electrospinning. Surfactants typically generate reverse micelles and other reverse supramolecular structures in organic solutions. ${ }^{38,39}$ Reverse micelles differ from normal micelles in that the head group sequesters itself into the micelle core and the hydrophobic tails reside in the shell of the micelle. 


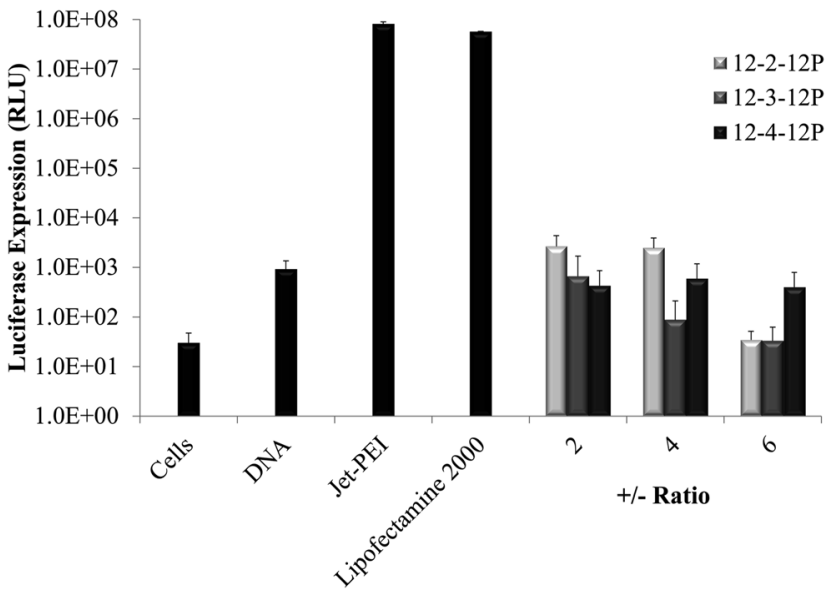

Fig. 4 Serum-free luciferase assay for phosphonium gemini surfactants.

Solution rheology of DTPP and all phosphonium gemini surfactants studied the solution behavior of the surfactants in chloroform. Fig. 5 reports the specific viscosity $v s$. concentration for all surfactants. In each plot, three different solution regimes were identified based upon a change in the slope of the data. $\mathrm{C}^{*}$ and $\mathrm{C}^{* *}$ were defined as the crossover points where each power law regression overlapped with the power law regression of the adjacent concentration regime. All surfactants displayed similar $\mathrm{C}^{*}$ transitions, occurring at $\sim 19 \mathrm{wt} \%$ in chloroform. $\mathrm{C}^{* *}$ depended significantly on the surfactant with DTPP displaying significantly a higher $\mathrm{C}^{* *}$ at $39 \mathrm{wt} \%$ compared to $30-32 \mathrm{wt} \%$ for the phosphonium gemini surfactants. The constraint of the head groups in the gemini surfactants presumably resulted in different supramolecular structures, which resulted in significant overlap of the structures in solution at lower concentrations. Soy lecithin, a phospholipid mixture, displayed a similar $\mathrm{C}^{* *}$ of $35 \mathrm{wt} \%$ in $70 / 30 \mathrm{v} / \mathrm{v}$ chloroform-DMF compared to the phosphonium gemini surfactants. $^{26}$

Polymer solution rheology utilizes the scaling parameters in each concentration regime to identify the solution behavior of the polymer. For instance, neutral, non-associating polymers display significantly different scaling factors compared to polyelectrolytes and the scaling factors provide information regarding the polymer solution conformation and solution behavior. ${ }^{40}$ All phosphonium gemini surfactants exhibited higher scaling factors compared to the DTPP control, especially in the concentrated regime above $\mathrm{C}^{* *}$. 12-2-12P gemini surfactant resulted in the highest scaling factors compared to all surfactants, likely due to the short ethylene spacer constraining the conformation of the head group. As a comparison, soy lecithin in 70/30 v/v chloroform-DMF displayed scaling factors of 2.4 and 8.4 in the semidilute and concentrated regimes, respectively. ${ }^{26}$ The phosphonium gemini surfactants exhibited similar semidilute scaling factors as soy lecithin, but their concentrated scaling factors were significantly lower than the concentrated scaling factor for soy lecithin.

Attempts at electrospinning DTPP and the phosphonium gemini surfactants examined the impact of the surfactant structure on fiber formation. All electrospinning attempts occurred at concentrations of $52 \mathrm{wt} \%$ or lower. DTPP and 12-4$12 \mathrm{P}$ gemini surfactant failed to generate any electrospun fibers, primarily electrospraying droplets. Conversely, 12-2-12P and 123-12P gemini surfactants sufficiently stabilized the electrospinning jet to generate electrospun fibers as shown in Fig. 6. At concentrations less than $52 \mathrm{wt} \%$, ill-defined fibers were formed with the incorporation of droplets or beaded fibers. Concentrations of $52 \mathrm{wt} \%$ were necessary to generate uniform, welldefined fibers. The 12-2-12P and 12-3-12P gemini surfactants
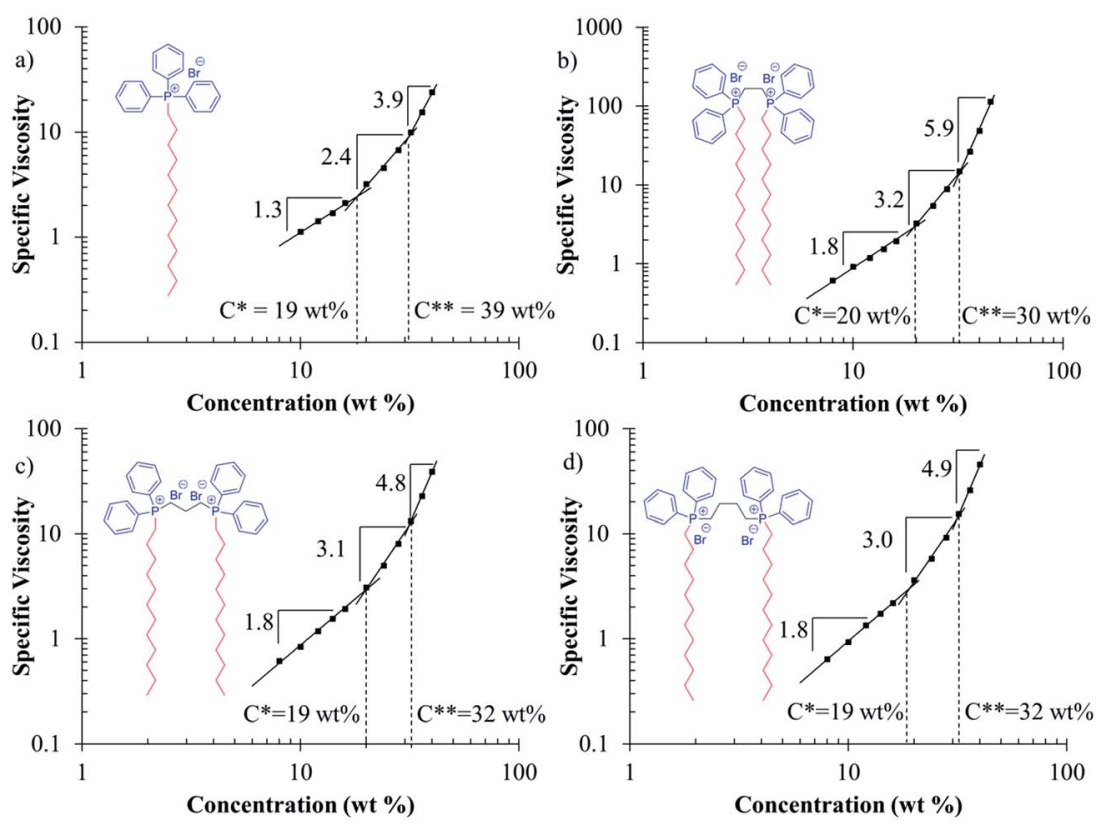

Fig. 5 Solution rheology of phosphonium control surfactant and phosphonium gemini surfactants in chloroform. 

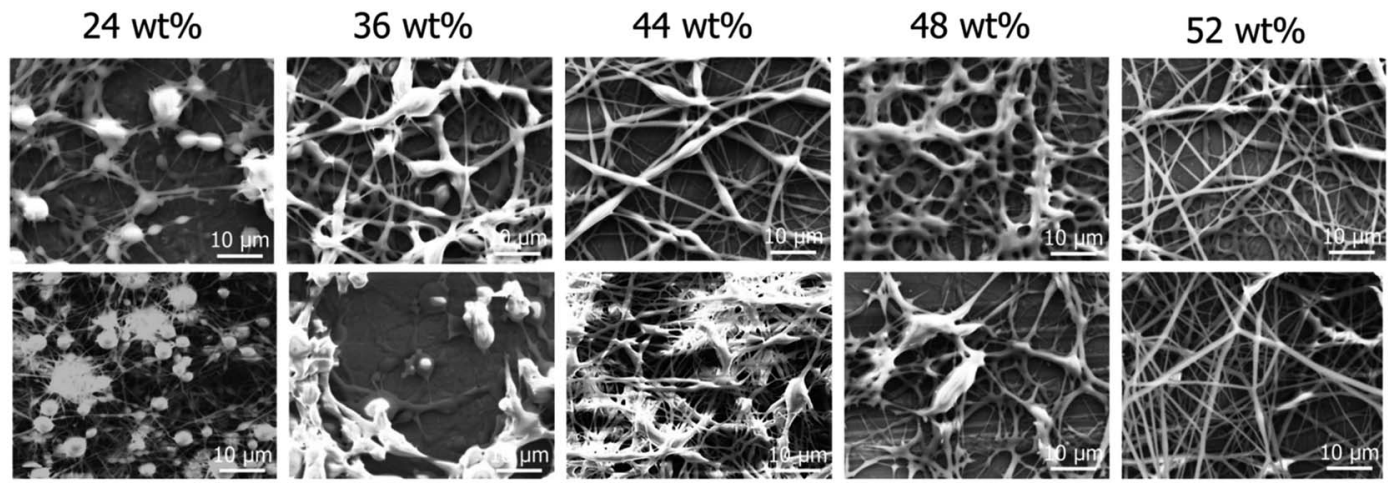

Fig. 6 SEM of electrospun phosphonium gemini surfactants from chloroform with the top images corresponding to the 12-2-12P gemini surfactant and the bottom images corresponding to the 12-3-12P gemini surfactant.

generated fibers diameters of $1.0 \pm 0.3 \mu \mathrm{m}$ and $1.1 \pm 0.2 \mu \mathrm{m}$, respectively, at $52 \mathrm{wt} \%$ in chloroform. As a comparison, aqueous solutions (50/50 $\mathrm{v} / \mathrm{v}$ water-methanol) of an ammonium gemini surfactant (12-2-12A) at concentrations of 42 and $44 \mathrm{wt} \%$ generated uniform fibers of 4 and $5 \mu \mathrm{m}$ diameters, respectively. ${ }^{20}$ Ultimately, spacers of 2 or 3 methylenes were necessary to generate a stable electrospinning jet to obtain uniform fibers. The longer alkyl spacer of 4 methylenes and the DTPP surfactant failed to generate electrospun fibers, presumably due to the absence of sufficient supramolecular entanglements.

\section{Conclusions}

The alkylation of ditertiary phosphines using 1-bromododecane generated phosphonium gemini surfactants in high yields. The cationic head groups displayed significant hydrophobicity due to the phenyl substituents leading to poor solubility in water. 12-2-12P and 12-3-12P gemini surfactants self-assembled into large supramolecular structures as shown with DLS. Due to limited solubility, isothermal titration calorimetry was ineffective in the determination of the CMC for 12-2-12P in pure water at $25^{\circ} \mathrm{C}$. As an alternative new ITC approach, the CMC of the 122-12P gemini surfactant was determined to be $1.0 \mathrm{mM}$ at $25^{\circ} \mathrm{C}$ in a mixed solvent of 50/50 v/v water-methanol. Preliminary biological assays focused on nucleic acid complexation, and demonstrated efficient nucleic acid binding for phosphonium gemini surfactants. However, the phosphonium gemini surfactants failed to efficiently deliver nucleic acids in vitro to HeLa cells. Phosphonium gemini surfactants were also studied in chloroform that promoted reverse micellar structures. Solution rheology elucidated the overall solution behavior of phosphonium gemini surfactants and DTPP in chloroform. Ultimately, electrospinning of $12-2-12 \mathrm{P}$ and $12-3-12 \mathrm{P}$ gemini surfactants generated uniform fibers with fiber diameters of $\sim 1 \mu \mathrm{m}$ while 12-4-12P and DTPP failed to electrospin.

\section{Acknowledgements}

This material is based upon work supported in part by the U.S. Army Research Office under grant number W911NF-07-1-0452 Ionic Liquids in Electro-Active Devices (ILEAD) MURI. This material is based upon work supported in part by the U.S. Army Research Laboratory and the U.S. Army Research Office under the Army Materials Center of Excellence Program, contract W911NF-06-2-0014. This material is partially based upon work supported by the National Science Foundation under Grant no. DMR-0923107. We acknowledge funding from NSF (CHE0722638) for the acquisition of our Agilent 6220 LC-TOF-MS. This material is based upon work supported by the Army Research Office (ARO) under Award no. W911NF-10-1-0307 (DURIP). The authors also acknowledge the Institute for Critical Technology and Applied Science (ICTAS) at Virginia Tech for facility support.

\section{References}

1 F. M. Menger and J. S. Keiper, Angew. Chem., Int. Ed., 2000, 39, 1906-1920.

2 F. M. Menger and C. Littau, J. Am. Chem. Soc., 1991, 113, 1451-1452.

3 F. Menger and C. Littau, J. Am. Chem. Soc., 1993, 115, 1008310090.

4 M. J. Castro, J. Kovensky and A. Fernández Cirelli, Langmuir, 2002, 18, 2477-2482.

5 X. Wang, J. Wang, Y. Wang, H. Yan, P. Li and R. K. Thomas, Langmuir, 2003, 20, 53-56.

6 M. Ao, G. Xu, Y. Zhu and Y. Bai, J. Colloid Interface Sci., 2008, 326, 490-495.

7 Y. Wang, Y. Han, X. Huang, M. Cao and Y. Wang, J. Colloid Interface Sci., 2008, 319, 534-541.

8 X. Huang, M. Cao, J. Wang and Y. Wang, J. Phys. Chem. B, 2006, 110, 19479-19486.

9 M. J. Rosen and L. D. Song, J. Colloid Interface Sci., 1996, 179, 261-268.

10 L. D. Song and M. J. Rosen, Langmuir, 1996, 12, 1149-1153. 11 M. J. Rosen, J. H. Mathias and L. Davenport, Langmuir, 1999, 15, 7340-7346.

12 M. Dreja and B. Tieke, Langmuir, 1998, 14, 800-807.

13 T. A. Camesano and R. Nagarajan, Colloids Surf., A, 2000, 167, 165-177.

14 M. Bergsma, M. L. Fielden and J. B. F. N. Engberts, J. Colloid Interface Sci., 2001, 243, 491-495. 
15 R. Oda, P. Panizza, M. Schmutz and F. Lequeux, Langmuir, 1997, 13, 6407-6412.

16 M. Johnsson, A. Wagenaar and J. B. F. N. Engberts, J. Am. Chem. Soc., 2002, 125, 757-760.

17 B. A. Pindzola, J. Jin and D. L. Gin, J. Am. Chem. Soc., 2003, 125, 2940-2949.

18 M. Zhou, P. R. Nemade, X. Lu, X. Zeng, E. S. Hatakeyama, R. D. Noble and D. L. Gin, J. Am. Chem. Soc., 2007, 129, 9574-9575.

19 F. Kern, F. Lequeux, R. Zana and S. J. Candau, Langmuir, 1994, 10, 1714-1723.

20 M. P. Cashion, X. Li, Y. Geng, M. T. Hunley and T. E. Long, Langmuir, 2009, 26, 678-683.

21 Z.-M. Huang, Y.-Z. Zhang, M. Kotaki and S. Ramakrishna, Compos. Sci. Technol., 2003, 63, 2223-2253.

22 D. H. Reneker, A. L. Yarin, H. Fong and S. Koombhongse, J. Appl. Phys., 2000, 87, 4531-4547.

23 M. G. McKee, M. T. Hunley, J. M. Layman and T. E. Long, Macromolecules, 2005, 39, 575-583.

24 S. L. Shenoy, W. D. Bates, H. L. Frisch and G. E. Wnek, Polymer, 2005, 46, 3372-3384.

25 M. G. McKee, G. L. Wilkes, R. H. Colby and T. E. Long, Macromolecules, 2004, 37, 1760-1767.

26 M. G. McKee, J. M. Layman, M. P. Cashion and T. E. Long, Science, 2006, 311, 353-355.

27 J. C. Singer, R. Giesa and H.-W. Schmidt, Soft Matter, 2012, 8, 9972-9976.
28 M. Chen, S. R. Nielsen, T. Uyar, S. Zhang, A. Zafar, M. Dong and F. Besenbacher, J. Mater. Chem. C, 2013, 1, 850-855.

29 A. Celebioglu and T. Uyar, J. Colloid Interface Sci., 2013, 404, 1-7.

30 G. Singh, A. M. Bittner, S. Loscher, N. Malinowski and K. Kern, Adv. Mater., 2008, 20, 2332-2336.

31 X. Yan, M. Zhou, J. Chen, X. Chi, S. Dong, M. Zhang, X. Ding, Y. Yu, S. Shao and F. Huang, Chem. Commun., 2011, 47, 7086-7088.

32 S. T. Hemp, M. Zhang, M. Tamami and T. E. Long, Polym. Chem., 2013, 4, 3582-3590.

33 M. Prasad, S. P. Moulik, A. MacDonald and R. Palepu, J. Phys. Chem. B, 2003, 108, 355-362.

34 K. Kalyanasundaram and J. Thomas, J. Am. Chem. Soc., 1977, 99, 2039-2044.

35 M. Pérez-Rodríguez, G. Prieto, C. Rega, L. M. Varela, F. Sarmiento and V. Mosquera, Langmuir, 1998, 14, 44224426.

36 S. P. Stodghill, A. E. Smith and J. H. O'Haver, Langmuir, 2004, 20, 11387-11392.

37 Z. Chu and Y. Feng, Langmuir, 2011, 28, 1175-1181.

38 P. K. Das and A. Chaudhuri, Langmuir, 1999, 16, 76-80.

39 P. Schurtenberger, R. Scartazzini, L. J. Magid, M. E. Leser and P. L. Luisi, J. Phys. Chem., 1990, 94, 3695-3701.

40 R. Colby, Rheol. Acta, 2010, 49, 425-442. 